\title{
Application of automated bioacoustic identification in environmental education and assessment
}

\author{
TERUYO OBA \\ Natural History Museum and Institute, Chiba, 955-2 Aoba-cho, Chuo-ku, Chiba 260-8682, Japan \\ Manuscript received on January 15, 2004; accepted for publication on February 5, 2004.
}

\begin{abstract}
Developments in electronics and computer science have led to the introduction of an automated bioacoustic identification device used to resolve commonly encountered problems in the identification of animal species in the field. This technology aids our auditory observations, and also improves the quality of biological surveys and environmental monitoring. In this paper the future roles and possibilities of bioacoustics are discussed, providing some examples from the realm of environmental education and monitoring that focus on the use of nature sounds.
\end{abstract}

Key words: automated species identification, bioacoustics, environmental education, monitoring environment, sound map.

\section{INTRODUCTION}

Biacoustics is an important field for the long-term monitoring, assessment and evaluation of the environment. Having a collection of sounds from the environment in local natural history museums can help in assessing how the species composition of an area changes over time. However, identification of species from bioacoustic recordings is a time consuming and difficult procedure.

Automated bioacoustic identification (ABI) is a method of automated signal analysis and recognition. A brief study of Japanese bird songs showed clear classification and identification using this method (Chesmore 1999). The benefit of ABI is its efficiency and accuracy of identification of species in the field. Furthermore, in view of nature protection and conservation, $\mathrm{ABI}$ may contribute to the long-term bioacoustic monitoring of remote loca-

E-mail: oba@chiba-muse.or.jp tions and also comparison of several different sites (Oba 1995).

Different methods have been proposed to sample and investigate the sound environment (Oba 1999). These methods were originally designed for scientific use but have been revised for the use of the general public. So far, the response to the bioacoustic approach is mixed. In my experience with the adults and children who participate in programs to learn to hear nature sounds, I have found that most of them are excited to learn nature sounds and sound environment. However, many complained that their improvement in identifying nature sounds was slow. While it is difficult to increase the rate of improvement in sound identification, recent technologies may make the training more enjoyable.

Increases in bioacoustic technology have played important roles in expanding research. ABI may be another means to increase the role of bioacoustics in different aspects of research and educa- 
tion. In the present communication, some examples of bioacoustic approaches to environmental monitoring, assessing and diagnosing environment and education are discussed to highlight some possibilities and potentials of using ABI.

\section{MONITORING THE SOUND ENVIRONMENT}

Next to the Natural History Museum in Chiba we have an Ecology Park that is a nature observation ground of approximately 6.6 ha, visited by over 80,000 people annually. Approximately half of the area is designated for a restoration project to reestablish different types of vegetation characteristic of the Boso peninsula (Nakamura and Oba 1993). As a part of the long-term monitoring of the restoration work, the sound environment was studied at two locations. The first was by the Funada-ike pond and the other in the laurel woodland. I made recordings of 6-15 minutes, 6 times a day, twice a month for 2 years (Oba 1994a). Every sample tape was analyzed for the natural sound sources including living and non-living things.

The result showed that the natural sound source composition (NSSC, a renamed term for SSSC, sound source species composition) well characterized the general structure of the natural sound environment with daily and seasonal changes at each location. NSSC was considered as a good index to evaluate not only the habitat differences but also the changing level of animal activities (Oba 1994b). Since there was no one else to identify sounds, it took me over 2 months to finish the data analysis and identification. While NSSC is considered a feasible acoustic index in long-term bioacoustic monitoring, it is not practical to spare such a long time to gain results. Here, application of ABI would be a useful method.

\section{ENVIRONMENTAL ASSESSMENT}

Being a unit range of local human activities, the primary school block (PSB) is one of the landscape areas for the study of local environments. Three primary school blocks that differ in landscape qual- ities and biodiversity were selected from agricultural community, residential area and new town in Chiba City to the east of Tokyo metropolis. Recordings of the sound environment were made monthly in 1991-1993. The sound environment was clearly different among the blocks in terms of NSSC. The natural sound diversity had an interesting implication to the biological diversity in terms of taxonomic distribution, locality bonds and trophic levels of natural sound sources. The potential of acoustic index in diagnosing the environment has been suggested (Oba 1995).

Kaisho Forest, a traditional landscape of rice fields surrounded by woodlands called sato-yama, was the last resort for city dwellers to enjoy nature and the rural environment. In the late 1980's, with the prospect of the 2005 World Exposition coming to Japan, it was revealed that the forest would be developed for the Expo site and later turned into a residential area. A group of citizens took notice of the quality of nature sounds as important factors for nature protection and environmental conservation of the forest. To challenge the environmental assessment from the viewpoint of forest users, I suggested sound mapping.

To generate a sound map, all acoustic events were recorded in a local area for a period of 6 minutes. Listeners then devise codes and symbols to differentiate sound sources, and plot them on a piece of paper to provide spatial and temporal information about the sounds. Colors, lines and size differences add further details of the sounds.

At Kaisho Forest, each person of the group drew a pair of sound maps: one at the planning site of sato-yama and the other at a control site of playground neighboring to some wooded area in the nearby new town (Fig. 1). Each pair of sound maps showed a marked contrast in natural sound diversity. By applying the NSSC analysis to the sound sources observed in the sound maps, some relevant comments on the natural sound diversity and its implication were given to help their diagnosis (Sogabe and Oba 2001). While sound mapping is an interesting method to examine how people perceive and 

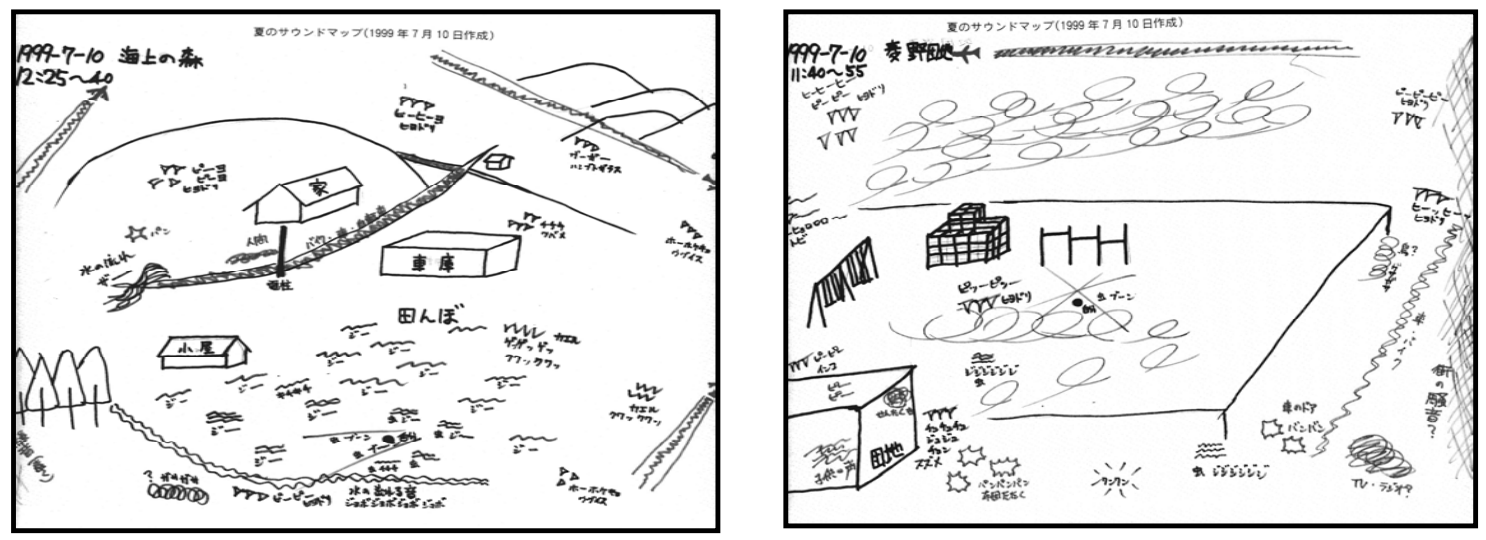

Fig. 1 - Sound mapping techniques to find differences in sound environments: the present sound environment of planned site of Expo 2005 (left) and the expected sound environment of similar site to the post-Expo development (Sogabe and Oba 2001).

evaluate the sound environment, $\mathrm{ABI}$ may help in NSSC analyses.

\section{SOUND ENVIRONMENTAL EDUCATION}

In the Ecology Park several courses to learn and experience nature sounds and sound environment are offered. The parent-child course deals with animal sounds such as birds, frogs, cicadas, crickets and bush crickets. For schoolteachers and local nature guides, we run a special course of nature sounds and environment to learn and exercise the skills in listening and recording sounds for the evaluation of sound environment. Although the voluntary participants appreciate these courses, it is hard to reach the public. One way to increase awareness is to seek the cooperation with local primary schools to promote the use of bioacoustics in the curriculum.

At primary schools, the teachers want children to listen to nature for the following three reasons. First, nature sounds are an attractive topic in science and comprehensive learning. Second, teachers expect children to polish their sense and sensibility by hearing nature sounds. Third, they would like children to realize the value and importance of quiet. However, there are many practical problems. When teachers ask children to listen to nature sounds outdoors, they do not know what to do exactly. The children cannot concentrate on listening for a long time and are easily distracted by visual things. In hearing certain sounds in the field, the children tend to hesitate in reproducing what they hear because they do not know how to describe their perception. Furthermore, most teachers cannot help children to identify nature sounds.

To solve these problems, we need a learning program specially designed to encourage children to listen to nature sounds. First, step-by-step procedures are required to cope with the different stages of development and varying degrees of outdoor experiences. The program must have a long-term perspective for the 6-year primary school curriculum, while offering practical learning modules with several choices and variations to fit in with daily teaching. Second, good educational tools, hands-on devices and reference materials are necessary to help the students make observation and identify sounds. $\mathrm{ABI}$ is a natural solution to these problems.

\section{ABI APPLICATION IN ENVIRONMENTAL EDUCATION}

The Ministry of Education and Science of Japan is interested in the cooperative developments between local museums and schools for the promotion of scientific understanding and environmental concern among children. I would like to describe the latest project "'Observe Nature by Ear! Preparation of the Learning Program Assisted by Vocal Recogni- 
tion Technology" funded by the JST Program for Community Science Centers and School Cooperative Development, 2003.

The learning program is intended to help children observe, describe and enjoy sounds in nature using ABI applications. Birds are chosen for the main subject to study because they are vocal all year round and bird watching provides children with enjoyable outdoor experiences. The program is comprised of three steps: 1) to be able to hear nature sounds, 2) to search for birds after sounds, and 3) to make a bird observation map. There are different tasks in each step: a) to get children interested in nature sounds, b) to keep their attention on the sounds for close observation, c) to help children identify birds by comparing different species, d) to supply a database of acoustic events and sound files for further learning, and e) to present the results of observation in an enjoyable way for sharing. While the conventional field signs, hands-on devices and activity sheets are helpful, ABI application is a new invention to solve the difficulty that the expert of hearing $(\mathrm{EH})$ faces.

Usually, many children have to share one EH in a class. Only a small number of children near EH can obtain the full advice, while the others either have difficulty in observation or are bored from lack of information and advice (Fig. 2 left). By introducing ABI device, children can concentrate on observing sounds even when they are alone. They are able to record a piece of sound and check it repeatedly with reference sounds. Here the ABI device offers a list of the most probable species for comparison. Children are encouraged to choose one of the species based on the acoustic features and other relevant information given in the $\mathrm{ABI}$ display and bird observation guidebook. EH is able to respond to different needs and questions of more individuals in a class (Fig. 2 right).

Every time children select the most probable species, the ABI device stores the following data: species selected from the list, time and location of the recording, probable level of ABI identification and the sound file. These data are transferred to the data management device to form the database. Thus, the bird observation map is ready for presentation and exhibition: it is a good way to accumulate and share results among different schools and visitors of the Ecology Park.

In late May-early June, the first step of learning program was tested in cooperation with the three primary schools in the Ecology Park. In the activity of "Birds call their names!" children were asked to put a good nickname to the birds after the characteristics of their sounds so that EH could tell them what bird it might be. Children went out for bird listening in groups of 2-4 persons. Each group had to list up to 10-15 features about sounds, calling spot, movement of body etc., from which they were to devise the best nickname. Later in the class, $\mathrm{EH}$ attempted to reproduce the sound and detect the name of bird. Children learnt that good nicknames led to identification and were amazed at the skill of EH. EH explained the importance of identification and meaning of the species. Then the engineers demonstrated the ABI device, a handheld computer (PDA) loaded with the AI-WIT Wildlife Information System developed by Kajima Co., Asahi Kasei Co., and InterRisk Research Institute and Consulting Inc. (Fig. 3). As children witnessed, the device could also identify birds; they were amazed and showed a great interest in using it in the next step of the learning program in autumn.

In the Ecology Park, different field signs were placed along the trail to ask different questions about sounds. Hands-on devices were also used to encourage them to listen (Fig. 4). Some actually play a sound by pushing the switch. The role of signs and devices seemed as important as ABI device to make children stop and listen, otherwise they kept walking along the trail without hearing.

Although the ABI device is to record sounds and relevant data in the second and third step of learning program, children still need to make notes and record their findings in the activity sheets. They are always important and useful in reviewing their field experience after going back to school.

Does the ABI device replace EH? It is a sim- 

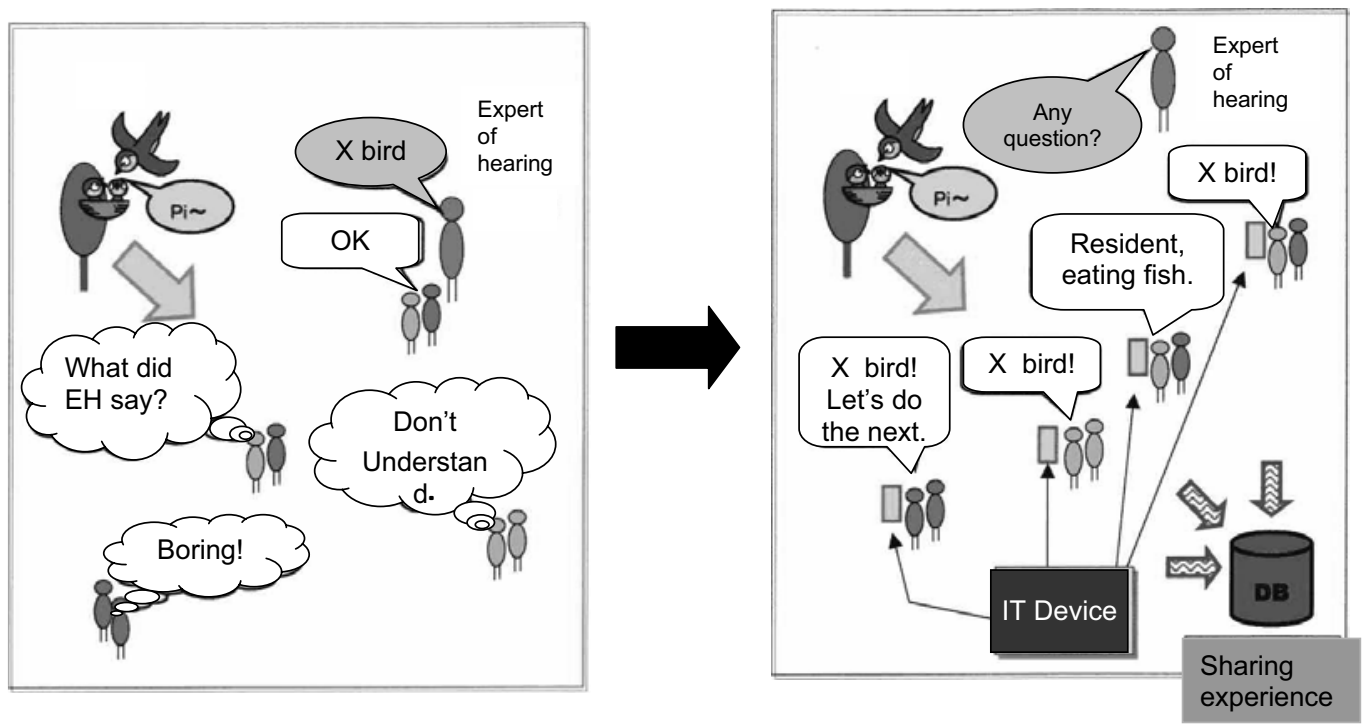

Fig. 2 - The role of ABI: limited access to the expert of hearing (left); the expert of hearing (EH) is assisted with ABI device and children are encouraged in voluntary observation (right).

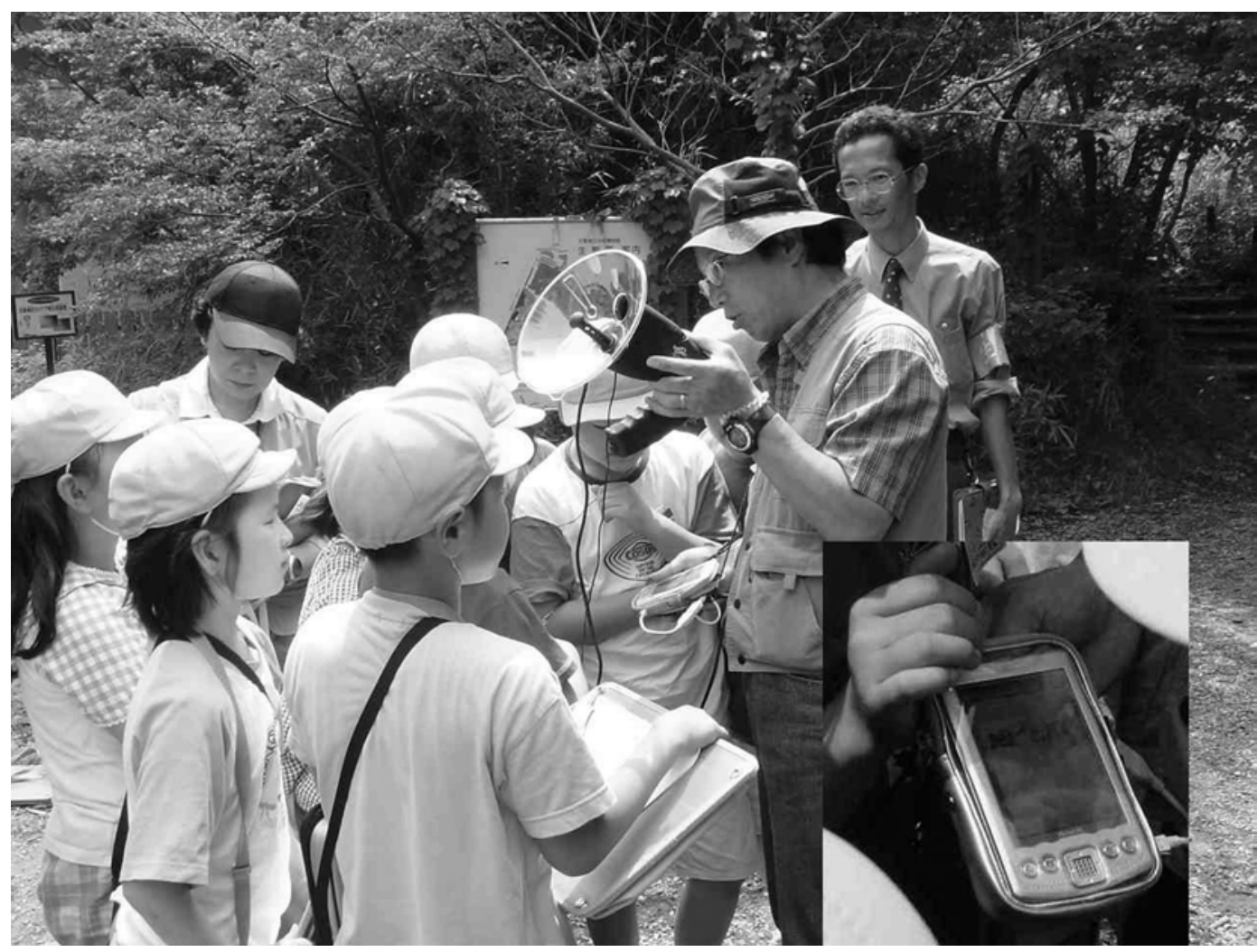

Fig. 3 - Demonstration and close-up view of the ABI device (photo by T. Maruyama). 


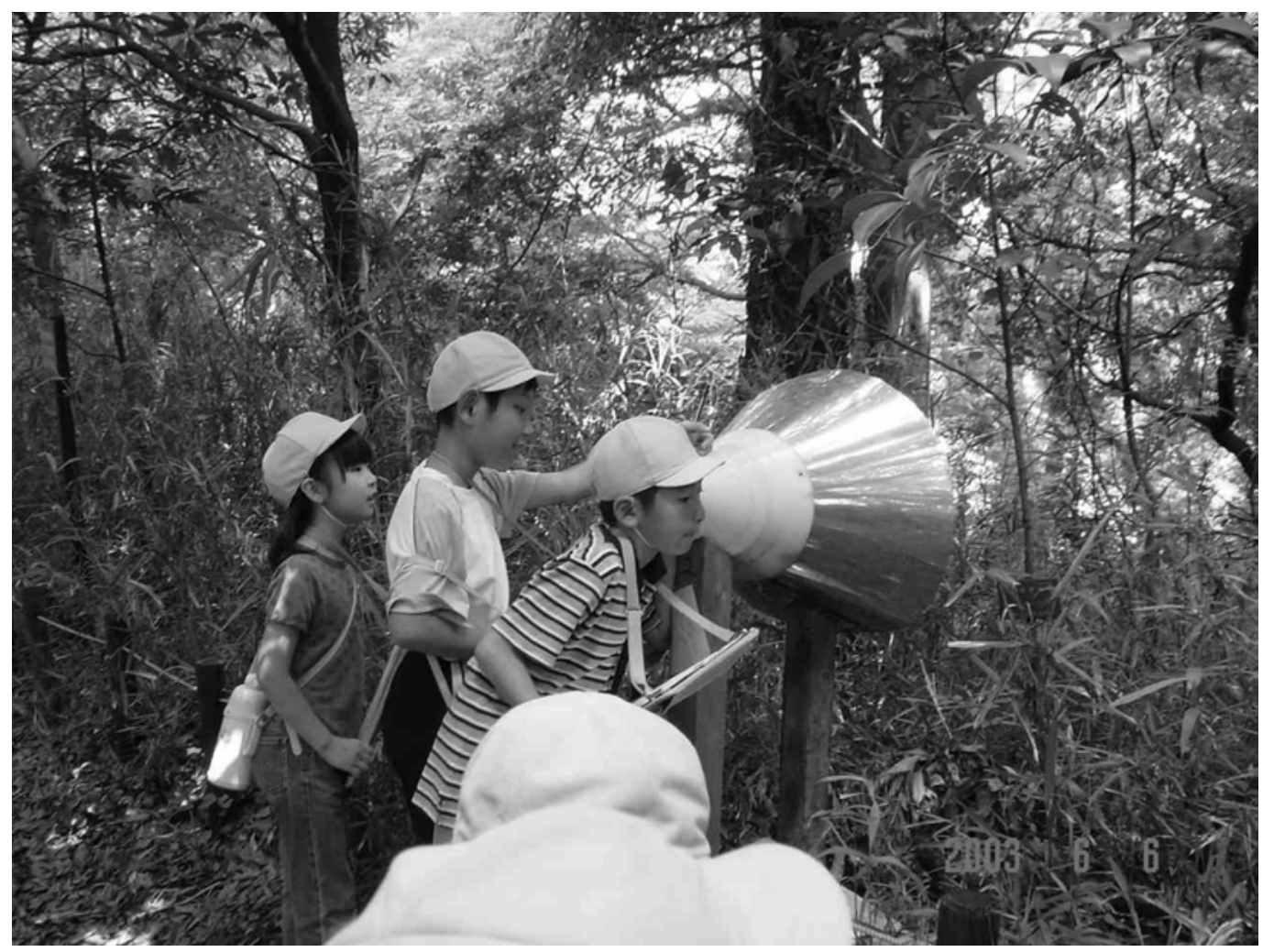

Fig. 4 - Hands-on devices are to encourage children to hear nature sounds (photo by T. Maruyama).

ple question that everybody asks. The answer is NO. In the process of learning, human contact is something we should never exclude. Children are well stimulated by meeting people. However, the $\mathrm{ABI}$ device needs to be easy to handle and precise in recognition. In the whole process of making a learning program assisted by $\mathrm{ABI}$ application, people of different fields and experiences are involved. To make the ABI device for educational purposes, there are different needs and requirement from the general use. It is good to know different views from schoolteachers, nature guides, bioacousticians, museum staffs and engineers.

\section{CONCLUSIONS}

1) $\mathrm{ABI}$ device is a new bioacoustic tool to resolve commonly encountered problems in the field identification of species. As an educational tool, ABI assists the learning program of hear- ing nature sounds to fit into the school needs.

2) As a tool for environmental monitoring and assessment, $\mathrm{ABI}$ is quite promising for nearly real-time monitoring of certain sets of local species.

3) It is necessary to establish voucher specimens of sounds for local species, as the Ecology Park Sound Environment Collection is doing.

\section{ACKNOWLEDGMENTS}

I greatly owe to Nobuko Ishii, Terumi Oami, Yukio Umesato, Yoko Ishida, Hiroshi Ikeda, Yasuko Ishii, Kenichi Kaneko, Hisako Kawazoe, Takeshi Kobayashi, Miyoko Matsuyama, Fumiko Aya, Yuko Misu, Hiroki Sawada, Makoto Shozakai, Makoto Haraguchi, Goshu Nagino, Toshie Maruyama, Namiko Suzuki, Ai Nakamura, Naoko Nobe, Kayako Ishii, and Staff of Natural History Museum and Institute Chiba. 


\section{RESUMO}

Avanços em eletrônica e em ciências da computação levaram ao desenvolvimento de um instrumento de identificação bioacústica automática utilizado para resolver os problemas encontrados freqüentemente na identificação das espécies animais no campo. Esta tecnologia ajuda nossas observações auditivas e também melhora a qualidade dos levantamentos biológicos e do monitoramento ambiental. Neste artigo, os futuros papéis e possibilidades da bioacústica são discutidos apresentando alguns exemplos do universo da educação ambiental e do monitoramento que focalizam o uso de sons da natureza.

Palavras-chave: identificação automática de espécies, bioacústica, educação ambiental, monitoramento ambiental, mapa sonoro.

\section{REFERENCES}

Chesmore D. 1999. Technology transfer: application for electronic technology in ecology and entomology for species identification. Nat Hist Res 6: 111-126.

NAKAmura T AND ObA T. 1993. Seitaien - Creating a collection of restored ecosystems in Chiba, Japan. Restoration and Management Notes 11: 25-30.

Ова T. 1994a. Sampling methods for the study of the natural sound environment in Japan: consideration of the sample time unit. Nat Hist Res 3: 27-32.
Ова T. 1994b. Sound environment of the pond shore and laurel wood in the Ecology Park (1991.4-1993.3): the study of natural sound source composition and examination of the methodology. J Nat Hist Mus Inst Chiba, Special Issue 1: 277-332 (in Japanese with English abstract).

ОвА Т. 1995. What is the natural sound diversity? A consideration for the local natural amenity. Nat Hist Res 3: 173-185.

Ова Т. 1999. Bioacoustic approach in environmental monitoring. J Nat Hist Mus Inst Chiba 5: 115-126 (in Japanese with English abstract).

Sogabe Y AND OBA T. 2001. Sound maps for diagnosing rich contact between men and nature. Proc Soundscape Ass Japan Conf, p. 15-18.

\section{Web site}

Natural History Museum and Institute Chiba: http://www.chiba-muse.or.jp/NATURAL/

The 2005 World Exposition, Aichi, JAPAN: http://www.expo2005.or.jp/language.html

JST Program for Community Science Centers AND School CoOperative Development: http://rika.jst.go.jp/chiiki/15/15.html\#05 